\title{
Systematic review of the effect of implementing enhanced recovery after surgery on selected attributes of surgical recovery in gynecology
}

\section{Jinekolojik cerrahide cerrahi iyileşmenin seçilmiş nitelikleri üzerinde cerrahi sonrası hızlandırılmış iyileşme kullanımının etkisinin sistematik derlemesi}

\author{
(1) Greg J Marchand ${ }^{1}$, (1) Catherine Coriell ${ }^{1}$, (1) Ahmed Taher ${ }^{3}$, (1) Alexa King ${ }^{2}$, (1) Stacy Ruther ${ }^{1}$, (1) Giovanna \\ Brazil $^{1}$, (1) Kaitlynne Cieminski ${ }^{1}$, (1) Nicolas Calteux ${ }^{1}$, (1) Hollie Ulibarri ${ }^{1}$, (1) Julia Parise ${ }^{1}$, (1) Amanda Arroyo ${ }^{1}$, \\ (1) Katelyn Sainz 1
}

${ }^{1}$ Marchand Institute for Minimally Invasive Surgery, Mesa, Arizona, USA

2 International University of Health Sciences, Basseterre, St. Kitts

${ }^{3}$ Fayoum University Faculty of Medicine, Fayoum, Egypt

\begin{abstract}
This study aimed to systematically review the available literature on enhanced recovery after surgery (ERAS) following gynecologic procedures performed either as an open surgery or as a minimally invasive gynecological surgery (MIGS) in terms of outcomes. This review revealed the results of published literature and assessed the benefits and diverse outcomes of ERAS implementation in patients undergoing MIGS or other gynecologic surgeries. In this review, we sought to examine the efficacy of entire ERAS protocols, faithfully performed, to determine whether they were successful in improving individual attributes of surgical recovery. Electronic databases of PubMed, Cochrane, Web of Science, Scopus, MEDLINE, and ClinicalTrials.gov were systematically searched in January 2021 for relevant studies. Data were extracted from eligible studies including LOS, change in the quality-of-life and recovery over time, postoperative complications including nausea and vomiting, opioid or anesthesia use, hospital cost, patient satisfaction, postoperative pain, and readmission rate as outcomes. Many of the included studies reported a significant reduction in the LOS as well as in readmission rates, hospital cost, and occurrence of nausea and vomiting postoperatively. Moreover, a clinically significant increase was noted in patient satisfaction in studies that have used tools that measure patient satisfaction. No studies have reported a significant increase in the overall quality of recovery using appropriately validated tools. Following ERAS implementation, patients' postoperative rehabilitation, including postoperative discomfort, readmission rates, and satisfaction, showed a clinically significant improvement.
\end{abstract}

Keywords: ERAS, enhanced recovery after surgery, ERAS protocols, recovery from surgery

Öz

Açık veya minimal invaziv jinekolojik cerrahi (MIGS) ile gerçekleștirilen jinekolojik prosedürlerin ardından "cerrahi sonrası hızlandırılmıș iyileșme" (ERAS) hakkında mevcut literatürü farklı sonuçlar açısından sistematik olarak gözden geçirmeyi amaçladık. Yayınlanmış literatürü gözler önüne serdik ve MIGS veya diğer jinekolojik cerrahi geçiren hastalarda ERAS uygulamasının faydalarını ve çeşitli sonuçlarını değerlendirdik. Cerrahi iyileşmenin bireysel özelliklerini iyileştirmede başarılı olup olmadıklarını belirlemek için, sadakatle uygulanan tüm ERAS protokollerinin etkinliğini incelemeye çalıştık. Güvenilir çalışmalar için Ocak 2021'de PubMed, Cochrane, Web of Science, Scopus, MEDLINE ve ClinicalTrials.gov'da sistematik olarak arama yaptık. Hastanede kalış süresi, yaşam kalitesindeki değissiklik ve zamanla iyileşme, bulantı ve kusma dahil postoperatif komplikasyonlar, opioid veya anestezi kullanımı, hastane maliyeti, hasta memnuniyeti, postoperatif ağn ve yeniden hastaneye kabul oranı gibi veriler, bu değerlendirilen sonlanımları içeren uygun çalışmalardan elde edildi. Dahil edilen birçok çalışma, ameliyat sonrası hastanede kalış süresinin yanı sıra yeniden kabul oranlarında, hastane maliyetinde ve ameliyat sonrası bulantı ve kusmada önemli bir azalma olduğunu bildirdi. Ayrıca, hasta memnuniyetini ölçmek için araçlar kullanan çalışmalarda hasta memnuniyetinde klinik olarak anlamlı bir artış olduğu görüldü. Hiçbir çalışma, uygun şekilde doğrulanmış araçlar kullanarak "toplam iyileşme kalitesinde" anlamlı bir artış bildirmedi. ERAS uygulamasının ardından, ameliyat sonrası rahatsızlık, yeniden kabul oranı ve memnuniyet dahil olmak üzere hastaların ameliyat sonrası rehabilitasyonunda klinik olarak anlamlı bir iyileşme gösterildi.

Anahtar Kelimeler: ERAS, ameliyat sonrası hızlandırılmış iyileşme, ERAS protokolleri, ameliyattan iyileşme

Address for Correspondence/Yazışma Adresi: Greg J Marchand MD,

Marchand Institute for Minimally Invasive Surgery, Mesa, Arizona, USA

Phone: +14806280566 E-mail: gm@marchandinstitute.org ORCID ID: orcid.org/0000-0003-4724-9148

Received/Geliș Tarihi: 11.05.2021 Accepted/Kabul Tarihi: 11.06.2021

${ }^{\oplus}$ Copyright 2021 by Turkish Society of Obstetrics and Gynecology

Turkish Journal of Obstetrics and Gynecology published by Galenos Publishing House 


\section{Introduction}

The concept of "enhanced recovery after surgery (ERAS)" was first studied in colorectal surgeries by Kehlet in the 1990s as a bundled pathway to accelerate recovery after surgery ${ }^{(1)}$. ERAS is a systematic approach to the entire perioperative period aiming to minimize surgical trauma, perioperative stress, and recovery time and maintain postoperative physical function ${ }^{(2,3)}$. In addition, ERAS protocols can improve mobilization after surgery $^{(4)}$. These benefits ideally will result in reduced length of hospital stay (LOS), complications, and hospital costs ${ }^{(5-7)}$.

ERAS protocols have now been implemented successfully in various surgical specialties, including gynecology ${ }^{(8)}$. The ERAS society recommends specific protocols in this specialty, which range from protocols for simple hysterectomy to complex cytoreductive cancer surgeries ${ }^{(9,10)}$. This society provides guidelines for the preoperative, intraoperative, and postoperative management of patients undergoing gynecological surgery and other types of surgery ${ }^{(11,12)}$. The ERAS protocols presented by ERAS society for preoperative patient preparation include multiple items such as educating and informing the patient extensively about the planned surgical and anesthetic procedures. Preoperative education and counseling may result in decreased anxiety and increased patient satisfaction, which in turn improve fatigue and promote early discharge ${ }^{(13,14)}$. Some of the other basic tools employed for preoperative preparation include avoidance of bowel preparation, minimization of preoperative fasting, prevention of surgical site infection, and provision of venous thromboembolism prophylaxis, perioperative nutrition, preoperative laxatives, and opioidsparing multimodal postoperative analgesia ${ }^{(15)}$.

The ERAS multimodal pain management program is considered a fundamental component in all ERAS protocols, as it can lower opioid consumption and its associated side effects such as sedation, urinary retention, constipation, and poor quality of recovery. This program involves preemptive administration of non-opioid analgesic and other medications such as gabapentin and acetaminophen, along with non-steroidal anti-inflammatory agents or cyclo-oxygenase 2 inhibitors ${ }^{(16-18)}$. These combinations of preemptive medications were reported to ease postoperative pain and postoperative nausea and vomiting (PONV). Therefore, the consumption of both antiemetic and analgesic drugs may be significantly reduced in patients undergoing these perioperative protocols $^{(16)}$.

Evidence-based guidelines for postoperative care in gynecologic oncology are also available from the ERAS society, including previously mentioned postoperative analgesia, postoperative control of glucose, prevention of postoperative ileus, postoperative thromboembolism prophylaxis, avoidance of peritoneal drainage, early mobilization, and provision of urinary drainage ${ }^{(12)}$. ERAS protocols and their associated outcomes have been widely studied after exploratory laparotomy in gynecologic surgery and gynecologic oncology. However, relatively little data address ERAS use in benign gynecology and minimally invasive gynecologic surgery (MIGS)(19-22).
MIGS is defined as the use of less invasive techniques such as hysteroscopy or laparoscopy. It requires fewer, smaller incisions (or no incisions at all) instead of one large incision, as is common in laparotomy. With the increased interest in MIGS, including hysterectomy, in the last decade, strategies to further improve outcomes are greatly required ${ }^{(23)}$. Several studies have recently addressed the effect of ERAS protocols on outcomes of MIGS. In 2016, Michener et al. ${ }^{(23)}$ analyzed some ERAS protocols implemented in patients with gynecologic cancer undergoing gynecologic surgery. Their retrospective case-control study showed that the LOS was decreased significantly in the ERAS group compared with the historical control group. The frequency of using narcotics (measured in morphine equivalents) also decreased in the ERAS group, but the pain scores were not significantly different between the two groups. In 2020, Lee et al. ${ }^{(22)}$ revealed that ERAS protocol adherence by women undergoing MIS for malignant and benign indications did not diminish the median LOS but reduced opioid consumption, hospital costs, and intravenous fluid use.

Given the relative abundance of recently published studies that have analyzed the effect of ERAS protocols on benign gynecology and MIGS, this review aimed to present findings of published studies that have assessed the benefits and diverse outcomes of ERAS implementation in patients undergoing an open surgery or MIGS.

\section{Materials and Methods}

\section{Search Strategy and Data Collection}

Electronic databases of PubMed, Cochrane, Web of Science, Scopus, and MEDLINE were systematically searched for all studies up to February 1, 2021. Any published results from ongoing studies using the ongoing trials registry of the US National Institutes of Health (http://www.clinicaltrials.gov) were also searched. The literature search was conducted using the following search key terms: (ERAS OR "ERAS" OR "enhanced recovery" OR "enhanced recovery pathway" OR ERP OR "fast-track" OR "fast-tract surgery") AND (MIGS OR "MIGS" OR laparoscopy OR "laparoscopic surgery" OR "robotic surgery" OR "robotic minimally invasive" OR "minimally invasive surgery" OR MIS). The search was limited to gynecology. A preferred reporting items for systematic reviews and metaanalyses (PRISMA) flowchart of the study selection process is shown in Figure 1.

The endnote software was used to remove duplicated studies, and all retrieved citations were screened for eligibility by screening their titles and abstracts first and then their full texts. Studies that matched the selection criteria were then included in the study. References of the included studies were also screened manually for additional relevant studies.

\section{Selection Criteria}

This study included randomized controlled trials (RCTs), cohort studies, and case-control studies that focused on the implementation of ERAS protocols in gynecologic surgeries, 


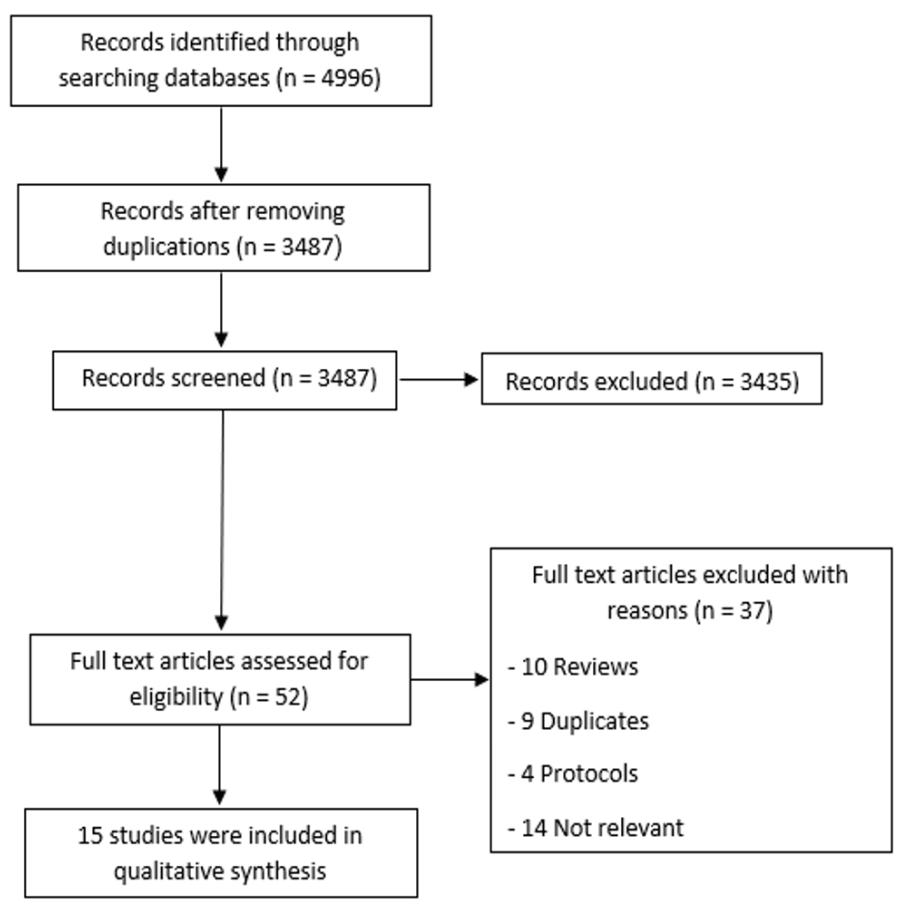

Figure 1. PRISMA flow diagram

PRISMA: Preferred reporting items for systematic reviews and meta-analyses

including oncology, benign gynecology, and MIGS. No restrictions for age, sex, site, or publication date were applied. Animal studies, non-English studies, thesis, reviews, and studies where the full text could not be obtained were excluded.

\section{Data Extraction}

Data related to the following were extracted: 1) summary of the included studies and baseline characteristics of their enrolled population including study design, number of patients and samples in each group, age, study outcomes, surgery type, rehabilitation protocol, and conclusion; 2) outcomes including LOS, change in the quality-of-life (QoL) and recovery over time, postoperative complications including nausea and vomiting, opioid or anesthesia use, hospital cost, patient satisfaction, postoperative pain, readmission rate, and ERAS pathway component; and 3) quality assessment questions and domains.

\section{Quality Assessment}

The quality of the included RCTs was assessed using Cochrane's risk-of-bias tool (version 1). This tool is found in Chapter 8.5 of the Cochrane Handbook of Systematic Reviews of Interventions 5.1.0. This tool consists of the following domains: sequence generation (selection bias), allocation sequence concealment (selection bias), blinding of participants and personnel (performance bias), blinding of outcome assessors (detection bias), incomplete outcome data (attrition bias), selective outcome reporting (reporting bias), and other bias. Author judgments fell into three categories, including a low, unclear, or high risk of bias for each domain.
The quality of the included cohort and case-control studies was assessed using the National Heart, Lung, and Blood Institute quality assessment tools ${ }^{(24)}$. These tools are composed of validated questions assessing the risk of bias and confounders. These questions were answered by "yes," "no," "not applicable," "cannot be determined," or "not reported." Finally, each study was given a score to guide the overall quality as "good," "fair," or "poor."

\section{Results}

\section{Literature Search}

The initial search yielded 4,996 articles from all searched databases. Of these 4,996 articles, 1,509 articles were excluded because of duplications, and titles and abstracts of 3,487 articles were screened. Moreover, 3,435 were excluded as they did not meet the inclusion criteria. The remaining 52 articles underwent full-text screening, of which 37 were excluded and 15 were finally included in the systematic review (PRISMA flow diagram; Figure 1).

\section{Quality Assessment of the Included Studies}

The overall quality of the included RCTs was high according to the Cochrane risk-of-bias tool ${ }^{(25-31)}$. According to the NIH quality assessment tool for observational cohort studies, only one study ${ }^{(32)}$ was graded as good, and the remaining seven studies $^{(22,33-38)}$ had fair quality. One case-control study ${ }^{(39)}$ had fair quality according to the NIH quality assessment tool for observational case-control studies. Full details of the quality assessments can be found in Supplementary Tables S1-3.

\section{Patients and Article Characteristics}

From the 15 included articles, eight have reported the LOS, readmission rate, and postoperative pain as outcomes. Five studies have reported the QoL and recovery score, opioid and anesthesia use, and patient satisfaction. Only two studies have reported hospital costs. Table 1 summarizes the characteristics of the included studies and outcomes reported after gynecological procedures.

\section{Outcome Measurements}

In this study, the prespecified outcomes that were used as the basis to assess the importance of ERAS implementation were as follows: LOS, change in the QoL and recovery score over time, and postoperative attributes including nausea and vomiting, opioid or anesthesia use, hospital cost, patient satisfaction, postoperative pain, and readmission rate.

\section{LOS}

In this study, LOS following the ERAS protocol for surgical intervention was considered as one of the main outcomes that determined the effect of ERAS on patients after surgeries. The ERAS approach may lead to substantial decreases in postoperative pain and LOS and faster return to baseline functioning after laparotomy in various surgical fields ${ }^{(25,26)}$. Dickson et al. ${ }^{(33)}$ 
Table 1. Summary and baseline characteristics of the included studies

\begin{tabular}{|c|c|c|c|c|c|c|c|c|}
\hline Study ID & Study design & $\begin{array}{l}\text { Number } \\
\text { of } \\
\text { patients }\end{array}$ & $\begin{array}{l}\text { Study arm, } \\
\text { number }\end{array}$ & $\begin{array}{l}\text { Age (years), } \\
\text { Mean } \pm \text { SD }\end{array}$ & $\begin{array}{l}\text { Study } \\
\text { outcomes }\end{array}$ & Surgery & $\begin{array}{l}\text { Rehab } \\
\text { protocol }\end{array}$ & Conclusion \\
\hline $\begin{array}{l}\text { Dickson et } \\
\text { al. 2012(33) }\end{array}$ & $\begin{array}{l}\text { Retrospective } \\
\text { review of } \\
\text { consecutive } \\
\text { cases, before } \\
\text { and after } \\
\text { design }\end{array}$ & 366 & $\begin{array}{l}\text { First period: } \\
\text { control } \\
\text { group }=86, \\
\text { experimental } \\
\text { group }=96, \\
\text { second period: } \\
\text { control } \\
\text { group }=90, \\
\text { experimental } \\
\text { group }=94\end{array}$ & $\begin{array}{l}\text { First period: } \\
\text { control group } \\
=45.75 \pm 6.5 \text {, } \\
\text { experimental } \\
\text { group } \\
=45 \pm 9.3 \\
\text { Second } \\
\text { period: } \\
\text { control group } \\
=45 \pm 9.5, \\
\text { experimental } \\
\text { group } \\
=45 \pm 9.3\end{array}$ & $\begin{array}{l}\text { Length } \\
\text { of stay, } \\
\text { estimated } \\
\text { blood loss, } \\
\text { duration } \\
\text { of surgery, } \\
\text { surgical } \\
\text { complications }\end{array}$ & $\begin{array}{l}\text { Total } \\
\text { abdominal } \\
\text { hysterectomy }\end{array}$ & $\begin{array}{l}\text { Rapid- } \\
\text { recovery } \\
\text { program }\end{array}$ & $\begin{array}{l}\text { Introducing a rapid- } \\
\text { recovery program was } \\
\text { associated with shorter } \\
\text { hospitalization and did } \\
\text { not appear to compromise } \\
\text { surgical outcome. }\end{array}$ \\
\hline
\end{tabular}

\begin{tabular}{|c|c|c|c|c|c|c|c|}
\hline $\begin{array}{l}\text { Ferraioli et } \\
\text { al. } 2020^{(34)}\end{array}$ & $\begin{array}{l}\text { Observational } \\
\text { retrospective } \\
\text { study }\end{array}$ & 92 & $\begin{array}{l}\text { Surgery group, } \\
92\end{array}$ & $61.6 \pm 8.17$ & $\begin{array}{l}\text { EVAN-G } \\
\text { score }\end{array}$ & $\begin{array}{l}\text { Robotic- } \\
\text { assisted or } \\
\text { laparoscopic } \\
\text { surgery }\end{array}$ & ERAS \\
\hline
\end{tabular}

\begin{tabular}{|c|c|c|c|c|c|c|}
\hline $\begin{array}{l}\text { Frumovitz } \\
\text { et al. } \\
2020^{(26)}\end{array}$ & $\begin{array}{l}\text { Randomized, } \\
\text { open-labeled } \\
\text { phase 3, non- } \\
\text { inferiority trial }\end{array}$ & 631 & $\begin{array}{l}\text { Open surgery } \\
\text { group =312, } \\
\text { MIS group } \\
=319\end{array}$ & $\begin{array}{l}\text { Open surgery } \\
\text { group } \\
=45.6 \pm 10.4 \\
\text { MIS group } \\
=45.4 \pm 1.4\end{array}$ & Quality-of-life & $\begin{array}{l}\text { Open or } \\
\text { minimally } \\
\text { invasive } \\
\text { radical } \\
\text { hysterectomy }\end{array}$ \\
\hline
\end{tabular}

Retrospective

\begin{tabular}{|c|c|c|c|c|c|c|}
\hline $\begin{array}{l}\text { Kanno et al. } \\
2019^{(35)}\end{array}$ & $\begin{array}{l}\text { single- } \\
\text { institution } \\
\text { study }\end{array}$ & 109 & $\begin{array}{l}\text { Surgery group } \\
=109\end{array}$ & $43 \pm 12.1$ & $\begin{array}{l}\text { Surgical } \\
\text { outcomes }\end{array}$ & $\begin{array}{l}\text { Radical } \\
\text { hysterectomy }\end{array}$ \\
\hline
\end{tabular}

"In this study, we showed a high patient satisfaction with the ERAS program. When comparing length of stay and complications, neither extended length of stay nor development of complications after minimally invasive surgery impacted patient satisfaction."

"Women with early-stage cervical cancer had similar postoperative quality-oflife 6 weeks after surgery and beyond regardless of whether they had open or minimally invasive radical hysterectomy."

"In this retrospective study, MIRH with a notouch isolation technique for stage IA to IBl cervical cancer was a safe approach in terms of oncological outcomes. However, every surgeon who treats early-stage cervical cancer should inform each patient of the results of the LACC trial because it has an exceedingly high impact."
Total

Total

Prospective,

Kroon et al. randomized $2010^{(27)}$ controlled study intravenous

anesthesia

group $=27$,

patient-

controlled

analgesia $=26$

\section{intravenous}

anesthesia

group

$=47 \pm 5.75$,

Patient-

controlled

analgesia

$=46 \pm 5$
PONV, bowel

function,

length of stay, Fast-track pain, surgical complications
TIVA, patientcontrolled analgesia (PCA)
"The TIVA peri- and postoperative care was an advantage over PCA in most respects." 


\section{de Lapasse Prospective}

et al.

$2008^{(38)}$

feasibility

study
Surgery group

$=35$
Surgery group

$=43.0 \pm 12.1$
Length of stay, patient satisfaction
Total

laparoscopic

hysterectomy
Anesthetic protocol

"Our protocol for analgesia, anesthesia, and early discharge ( 24 hours after surgery) may be safely proposed after total LH in selected patients. Satisfaction rate of patients on postoperative days 7 and 30 was very high."

"The two groups were in general equally able to achieve most of the milestones despite differences in symptoms such as pain, nausea and confidence in mobilizing and going home. Preoperative education can empower patients. There is a high level of patient satisfaction in both groups."

"The need for postoperative hospitalization was median $24 \mathrm{hr}$ after vaginal surgery in a fast-track setting, independently of the complexity of the

\begin{tabular}{|c|c|c|c|}
\hline $\begin{array}{l}\text { Ottesen et } \\
\text { al. } 2002^{(37)}\end{array}$ & $\begin{array}{l}\text { Prospective } \\
\text { descriptive }\end{array}$ & 41 & $\begin{array}{l}\text { Surgery group } \\
=41\end{array}$ \\
\hline
\end{tabular}
study
Length of Vaginal stay, patient prolapse satisfaction surgery
Multimodal rehabilitation model
Randomized double-

Pauls et al. blinded 2015 (28) placebocontrolled trial

\section{Placebo group $=36$, dexamethasone group $=27$}

Quality of

Placebo group $=62.0 \pm 9.6$; group $=63.2 \pm 8.3$

\section{recovery,} postoperative vomiting, pain, voiding function

\section{Vaginal}

reconstructive

surgery for pelvic organ prolapses
Conventional

Peters et al. Retrospective $2020^{(36)}$
410
Conventional perioperative

perioperative care care, 214; $\quad=33.6 \pm 10.2$, enhanced recovery after surgery, 196 enhanced

recovery after surgery $=35.1 \pm 11.3$
Postoperative nausea and vomiting
Nonhysterectomy gynecologic procedures
ERAS procedure performed. Short term success rate, satisfaction rates, and acceptability were all excellent. Follow-up has been established to evaluate long-term success rates and recurrence."

"Use of dexamethasone prior to vaginal reconstructive surgery was associated with less nausea/vomiting and need for antiemetics, as well as greater success with voiding trials. Furthermore, QOR was enhanced, suggesting use of dexamethasone should be considered for these patients."

"Enhanced recovery after surgery implementation resulted in increased sameday discharge rates and improved perioperative outcomes without affecting 30-day morbidity in women undergoing laparoscopic minimally invasive non-hysterectomy gynecologic procedures." 


\begin{tabular}{|c|c|c|c|c|c|c|c|}
\hline $\begin{array}{l}\text { Ravndal and } \\
\text { Vandrevala. } \\
2016^{(29)}\end{array}$ & $\begin{array}{l}\text { Randomized } \\
\text { double- } \\
\text { blinded } \\
\text { placebo- } \\
\text { controlled } \\
\text { trial }\end{array}$ & 24 & $\begin{array}{l}\text { Intervention } \\
\text { group, 12; } \\
\text { control group, } \\
12\end{array}$ & - & Pain & $\begin{array}{l}\text { Laparoscopic } \\
\text { surgery }\end{array}$ & $\begin{array}{l}\text { Enhanced } \\
\text { recovery } \\
\text { program }\end{array}$ \\
\hline $\begin{array}{l}\text { Weston et } \\
\text { al. } 2020^{(32)}\end{array}$ & $\begin{array}{l}\text { Retrospective } \\
\text { study }\end{array}$ & 226 & $\begin{array}{l}\text { Pre-ERAS } \\
\text { group }=99, \\
\text { post-ERAS } \\
\text { group }=127\end{array}$ & $\begin{array}{l}\text { Pre-ERAS } \\
\text { group } \\
=58.83 \pm 11.92 \text {, } \\
\text { post-ERAS } \\
\text { group } \\
=58.25 \pm 12.88\end{array}$ & $\begin{array}{l}\text { Opioid use, } \\
\text { pain }\end{array}$ & $\begin{array}{l}\text { Minimally } \\
\text { invasive } \\
\text { (straight stick } \\
\text { laparoscopic, } \\
\text { single- } \\
\text { incision } \\
\text { laparoscopic, } \\
\text { or robotic- } \\
\text { assisted) } \\
\text { hysterectomy }\end{array}$ & $\begin{array}{l}\text { MIS-ERAS } \\
\text { protocol }\end{array}$ \\
\hline
\end{tabular}

\begin{tabular}{|c|c|c|c|}
\hline $\begin{array}{l}\text { Wodlin et } \\
\text { al. } 2011^{(30)}\end{array}$ & $\begin{array}{l}\text { Secondary } \\
\text { analysis from } \\
\text { an open } \\
\text { multicenter, } \\
\text { prospective } \\
\text { randomized } \\
\text { controlled trial }\end{array}$ & 162 & $\begin{array}{l}\text { General } \\
\text { anesthesia group } \\
=82, \text { spinal } \\
\text { anesthesia }=80\end{array}$ \\
\hline
\end{tabular}

Pain, postoperative nausea and vomiting, drowsiness, fatigue, postoperative pruritus
"Preemptive local anesthetics in the trocar areas are shown to be beneficial in laparoscopic gynecologic surgery within an enhanced recovery program. Movementevoked pain is far more intense than pain at rest."

"Enhanced recovery after minimally invasive surgery protocol implementation is an effective means to reduce opioid use, both in the intraoperative and postoperative phases of care among gynecologic oncology patients undergoing minimally invasive hysterectomy."

"Spinal anesthesia with intrathecal morphine carries advantages regarding postoperative symptoms and recovery following fast-track abdominal hysterectomy."

"In the setting of minimally invasive myomectomy, the use of a multimodal analgesic protocol improved postoperative recovery, resulting in (an) earlier hospital discharge."

"The ERAS program in benign $\mathrm{VH}$ reduces length of stay by $51.6 \%$ and enables more women to be discharged within 24 hours, with no increase in patient readmissions rates."

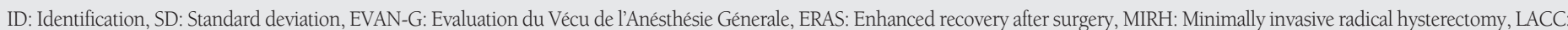

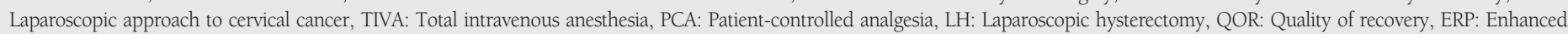
recovery protocol, MIS-ERAS: Minimally invasive surgery-enhanced recovery after surgery, VH: Vaginal hysterectomy

found that the median LOS shortened dramatically from 3 days before the implementation to 1 day after the implementation of their ERAS protocol (Rapid-recovery protocol) ( $<<0.001$ ). In their study of 35 patients, de Lapasse et al. ${ }^{(38)}$ found that 34 (97.1\%) patients were discharged the day after surgery and only one patient was not discharged on the surgeon's instructions because of technical difficulties during the procedure. Ottesen et al. ${ }^{(37)}$ reported that postoperative LOS was also 1 day for all patients, except for 3 (7.3\%) patients who were discharged later than $48 \mathrm{~h}$. Peters et al. ${ }^{(36)}$ reported that the ERAS implementation significantly increased the same-day discharge rate by $9.4 \%$. Clinically, the ERAS protocol remained effective, with 96.9\% of the patients discharged on postoperative day $0(\mathrm{p}<0.005)$ after excluding those planned postoperative admissions for medical conditions not related to the surgery ${ }^{(36)}$. Yoong et al. ${ }^{(39)}$ found that after ERAS implementation, the median LOS was reduced by $51.6 \%$ ( 22.0 vs $45.5 \mathrm{~h} ; \mathrm{p}<0.01$ ), and the proportion of patients discharged within $24 \mathrm{~h}$ was increased by fivefold (78.0 vs $15.6 \%$; $\mathrm{p}<0.05$ ). 
Table S1. Quality assessment of the cohort studies by NIH tool

\begin{tabular}{|c|c|c|c|c|c|c|c|c|}
\hline Domains & $\begin{array}{l}\text { Weston } \\
2020\end{array}$ & $\begin{array}{l}\text { Dickson } \\
2012\end{array}$ & $\begin{array}{l}\text { Ferraioli } \\
2010\end{array}$ & $\begin{array}{l}\text { Kanno } \\
2019\end{array}$ & $\begin{array}{l}\text { Peters } \\
2020\end{array}$ & $\begin{array}{l}\text { Lee } \\
2018\end{array}$ & $\begin{array}{l}\text { Ottesen } \\
2002\end{array}$ & $\begin{array}{l}\text { Lapasse } \\
2008\end{array}$ \\
\hline $\begin{array}{l}\text { 1. Was the research question or objective in this } \\
\text { paper clearly stated? }\end{array}$ & Yes & Yes & Yes & Yes & Yes & Yes & Yes & Yes \\
\hline $\begin{array}{l}\text { 2. Was the study population clearly specified and } \\
\text { defined? }\end{array}$ & Yes & Yes & Yes & Yes & Yes & Yes & No & Yes \\
\hline $\begin{array}{l}\text { 4. Were all the subjects selected or recruited } \\
\text { from the same or similar populations? Were } \\
\text { inclusion and exclusion criteria for being in the } \\
\text { study pre-specified and applied uniformly to all } \\
\text { participants? }\end{array}$ & Yes & Yes & Yes & Yes & Yes & Yes & Yes & Yes \\
\hline
\end{tabular}

5. Was a sample size justification, power $\begin{array}{llllllllllllll}\text { description, or variance and effect estimates } & \text { Yes } & \text { Yes } & \text { NR } & \text { No } & \text { Yes } & \text { NR } & \text { NR }\end{array}$ provided?

6. For the analyses in this paper, were the exposure(s) of interest measured prior to the outcome(s) being measured?

Yes Yes Yes Yes Yes Yes Yes No

7. Was the time frame sufficient so that one could reasonably expect to see an association between $\quad$ Yes $\quad$ Yes $\quad$ Yes Yes Yes Yes Yes exposure and outcome if it existed?

8. For exposures that can vary in amount or level, did the study examine different levels of the exposure as related to the outcome (e.g., NA NA NA NA NA

NA

NA

NA categories of exposure, or exposure measured as continuous variable)?

9. Were the exposure measures (independent variables) clearly defined, valid, reliable, and implemented consistently across all study participants?

\section{Was the exposure(s) assessed more than once} over time?

NA

NA

NA

NA

NA

NA

NA

NA

11. Were the outcome measures (dependent variables) clearly defined, valid, reliable, and implemented consistently across all study Yes $\begin{array}{llllll} & \text { No } & \text { No } & \text { No }\end{array}$ participants?

12. Were the outcome assessors blinded to the exposure status of participants?

No

13. Was loss to follow-up after baseline $20 \%$ or less?

Yes Yes

14. Were key potential confounding variables measured and adjusted statistically for their impact on the relationship between exposure(s) an outcome(s)?

Total scores (Yes $=1$, No $=0.5$, NR \& NA \& CD $=0$ )

Quality rating: good (10-14 point) or fair (7-10 point) or poor (0-7 points)

$\begin{array}{llllllll}10.5 & 9.5 & 8.5 & 8.5 & 8.5 & 9 & 8 & 8 \\ \begin{array}{l}\text { Good } \\ \text { quality }\end{array} & \begin{array}{l}\text { Fair } \\ \text { quality }\end{array} & \begin{array}{l}\text { Fair } \\ \text { quality }\end{array} & \begin{array}{l}\text { Fair } \\ \text { quality }\end{array} & \begin{array}{l}\text { Fair } \\ \text { quality }\end{array} & \begin{array}{l}\text { Fair } \\ \text { quality }\end{array} & \begin{array}{l}\text { Fair } \\ \text { quality }\end{array} & \begin{array}{l}\text { Fair } \\ \text { quality }\end{array}\end{array}$


Table S2. Quality assessment of the case control studies by NIH tool \begin{tabular}{l|l} 
Domains & Yoong \\
& 2014
\end{tabular}

1. Was the research question or objective in this paper clearly stated?

Yes

2. Was the study population clearly specified and defined? Yes

3. Was the participation rate of eligible persons at least $50 \%$ ?

NR

4. Were all the subjects selected or recruited from the same or similar populations? Were inclusion and exclusion criteria for being in the study pre-specified and applied uniformly to all participants?

5. Was a sample size justification, power description, or variance and effect estimates provided?

6. For the analyses in this paper, were the exposure(s) of interest measured prior to the outcome(s) being Yes measured?

7. Was the time frame sufficient so that one could reasonably expect to see an association between exposure Yes and outcome if it existed?

8. For exposures that can vary in amount or level, did the study examine different levels of the exposure as related to the outcome (e.g., categories of exposure, or NA exposure measured as continuous variable)?

9. Were the exposure measures (independent variables) clearly defined, valid, reliable, and implemented

consistently across all study participants?

10. Was the exposure(s) assessed more than once over time?

11. Were the outcome measures (dependent variables) clearly defined, valid, reliable, and implemented No consistently across all study participants?

12. Were the outcome assessors blinded to the exposure status of participants?

NR

13. Was loss to follow-up after baseline $20 \%$ or less?

14. Were key potential confounding variables measured and adjusted statistically for their impact on the relationship between exposure(s) an outcome(s)?

Total scores (Yes $=1$, No $=0.5$, NR \& NA \& CD =0) 8

Quality rating: good (14-13 point) or fair (8-12 point) or poor (7-0 points)

Fair quality

NA: Not applicable, NR: Not reported

\section{Change in the QoL and Quality of Recovery Over Time}

Although subjective, several tools have been developed to measure the QoL and recovery over time elements of postoperative care. Among the included studies, only one measured these attributes and did so using the Functional Assessment of Cancer Therapy tool for Cervical Cancer (FACT$\mathrm{Cx})$. Frumovitz et al. ${ }^{(26)}$ found no differences in the mean QoL score based on FACT-Cx scores between the non-ERAS and ERAS groups.

\section{Postoperative Attributes}

Postoperative complications can be prevalent in the field of open surgery. Dickson et al. ${ }^{(33)}$ reported no clinically significant differences between the ERAS group and the control group regarding complications. Pauls et al. ${ }^{(28)}$ reported that the rates of PONV were not significantly different between the two groups. However, Ferraioli et al. ${ }^{(34)}$ found that 50 (54.3\%) patients did not experience any PONV in the ERAS group and 14 (15.2\%) patients and 15 (16.3\%) patients experienced mild and slight nausea, respectively. Ottesen et al. ${ }^{(37)}$ reported minimal complications after implementation of their ERAS protocol (named "fast track" vaginal surgery) with urinary retention exceeding $450 \mathrm{~mL}$ and urinary tract infection $(12.2 \%$ and $9.8 \%$, respectively) as the most frequent complications. Peters et al. ${ }^{(36)}$ reported that PONV was twice as common in the conventional group than in the ERAS group.

\section{Opioid or Anesthesia Use}

Many studies have discussed the use of opioids or anesthesia perioperatively. Dickson et al. ${ }^{(33)}$ reported that local anesthesia improved pain in the experimental group by $83 \%$, reflecting increased use of rapid-recovery modalities $(\mathrm{p}<0.001)$. Wodlin et al. ${ }^{\left({ }^{30}\right)}$ reported that women who had undergone hysterectomy under spinal anesthesia with intrathecal morphine experienced significantly less postoperative discomfort compared with those who have undergone surgery under general anesthesia. However, PONV were reported equally in the two groups; vomiting significantly more often occurred during the first day after surgery in the spinal anesthesia group.

\section{Hospital Cost}

Hospital cost can be difficult to measure secondary to variables such as area and comorbidities, which can be difficult to control for. However, a general cost reduction associated with ERAS implementation was found, likely secondary to decrease LOS. Chapman et al. ${ }^{(25)}$ observed that the average total hospital costs were reduced by $12 \%$ in the ERAS group $(\$ 13,771)$ compared with $\$ 15,649$ ( $\mathrm{p}=0.01$ ). Moreover, Modesitt et al. ${ }^{(20)}$ found that hospital costs were significantly decreased by approximately $20 \%$ in both ERAS groups that underwent vaginal surgery.

\section{Patient Satisfaction}

Despite its subjective nature, many surgeons recognized patient satisfaction as one of the most important intraoperative criteria. Ferraioli et al. ${ }^{(34)}$ found that from a total of 92 patients who received the ERAS protocol, 56 (60.8\%) and 30 (32.6\%) patients were "very satisfied" and "quite satisfied" with the quality of care received, respectively. In addition, 6 (9.6\%) patients were "averagely satisfied," and no patients were dissatisfied with the care provided. Moreover, de Lapasse et al. ${ }^{(38)}$ reported that of 35 women undergoing their ERAS protocol, 34 (97.1\%) were satisfied with the procedure and all (100\%) patients would 
Table S3. Quality assessment of RCTs by Cochrane tool

\begin{tabular}{l|l|l} 
Domain & Risk of Judgment of the authors
\end{tabular}

(Frumovitz 2020)

Random sequence generation (selection

bias)

Low risk "Randomization was done using a computerized minimization program"

Allocation concealment

(selection bias)

Blinding of participants and personnel (performance bias)

High risk "Neither participants nor investigators were masked to treatment allocation"

Blinding of outcome assessment

(Detection bias)

Low risk No blinding, but the review authors judge that the outcome and the outcome measurement are not likely to be influenced by lack of blinding

Incomplete outcome data (attrition bias)

High risk

"Open label study, neither participants nor investigators were masked to treatment allocation"

Selective reporting (reporting bias)

Low risk

"The proportion of missing outcomes compared with observed event risk not enough to have a clinically relevant impact on the intervention effect estimate"

Other bias

Unclear risk Insufficient information to permit judgement of "Yes" or "No".

High risk The study protocol has not been reported.

\section{(Kroon 2010)}

Random sequence generation (selection bias)

Low risk

"The patients were prospectively randomized into two groups using the closedenvelope technique" not stated if the envelope was opaque or not.

Allocation concealment (selection bias)

Blinding of participants and personnel (performance bias)

Unclear risk

Low risk

Blinding of outcome assessment (detection bias)

High risk Not reported but the study seems to be an open label.

Incomplete outcome data (attrition bias) Low risk No loss of follow-up

Selective reporting (reporting bias)

Other bias

Unclear risk

High risk

The study protocol has not been reported.

(Pauls 2015)

Random sequence generation (selection bias)

Low risk

Allocation concealment (selection bias) Low risk

Blinding of participants and personnel (performance bias)

Low risk

Blinding of outcome assessment

(detection bias)

Low risk

Incomplete outcome data (attrition bias) Low risk

Selective reporting (reporting bias) Low risk

Other bias

Low risk

(Ravndal 2016)

Random sequence generation (selection bias)
Low risk
"Randomization schedule was conducted using a computer-generated table into two groups"

"The patient, physicians, anesthesia personnel, nursing, data collection staff and statistician were all blinded"

"The patient, physicians, anesthesia personnel, nursing, data collection staff and statistician were all blinded"

"The patient, physicians, anesthesia personnel, nursing, data collection staff and statistician were all blinded"

All patients that received interventions were included in the analysis

The study protocol is available and all of the study's pre-specified (primary and secondary) outcomes that are of interest in the review have been reported in the prespecified way;

The study appears to be free from any other sources of bias
"Participants were computer randomized in blocks of 6 by an independent statistician, and the list was delivered to the hospital pharmacy in a sealed envelope." 
Allocation concealment (selection bias) Low risk

Blinding of participants and personnel (performance bias)

Blinding of outcome assessment (detection bias)

Incomplete outcome data (attrition bias) Low risk

Selective reporting (reporting bias) Low risk
"The randomization list contained numbers from 1 to 24 and the allotted local anesthesia or placebo coded groups A and B. The pharmacist then decided which group bupivacaine and saline should represent, and the code was concealed until the end of the study."

"The surgeon, the hospital staff, and the participating women were all blinded to what the syringes contained."

"The surgeon, the hospital staff, and the participating women were all blinded to what the syringes contained."

"Only one case was excluded from the analysis"

The study protocol is available and all of the study's pre-specified (primary and secondary) outcomes that are of interest in the review have been reported in the prespecified way;

Other Bias

Low risk

(Wodlin 2011)

Random sequence generation (selection

bias)

Allocation concealment (selection bias)

Blinding of participants and personnel (performance bias)

Blinding of outcome assessment (detection bias)

Incomplete outcome data (attrition bias) High risk

Selective reporting (reporting bias) Low risk

Other bias

Low risk

Unclear risk Insufficient information to permit judgement

Unclear risk Insufficient information to permit judgement

High risk "The study was not blinded"

High risk "The study was not blinded"

Loss of follow-up was high without any reported reasons

The study protocol is available and all of the study's pre-specified (primary and secondary) outcomes that are of interest in the review have been reported in the prespecified way;

(Xiromeritis 2011)

Random sequence generation (selection bias)

Low risk

$$
\text { The study appears to be free from any other sources of bias }
$$

\begin{tabular}{|c|c|c|}
\hline Allocation concealment (selection bias) & Low risk & $\begin{array}{l}\text { "Neither medical staff nor patients involved in the study were aware of the } \\
\text { randomised assignment." }\end{array}$ \\
\hline $\begin{array}{l}\text { Blinding of participants and personnel } \\
\text { (performance bias) }\end{array}$ & Unclear risk & Insufficient information to permit judgement of "Yes" or "No". \\
\hline $\begin{array}{l}\text { Blinding of outcome assessment } \\
\text { (detection bias) }\end{array}$ & Low risk & $\begin{array}{l}\text { "A physician (NP) who was not aware of the assignment conducted postoperative } \\
\text { follow-up." }\end{array}$ \\
\hline Incomplete outcome data (attrition bias) & Low risk & No loss of follow-up was reported \\
\hline Other bias & Low risk & The study appears to be free from any other sources of bias \\
\hline
\end{tabular}

RCTs: Randomized controlled trials

recommend it to other patients. Ottesen et al. ${ }^{(37)}$ reported that the patients' satisfaction rate for their protocol ranged from $85.4 \%$ to $95.1 \%$.

\section{Postoperative Pain}

Ferraioli et al. ${ }^{(34)}$ observed that 29 (31.5\%) patients reported not experiencing any postoperative pain in the ERAS group. In addition, $30(32.6 \%)$ and 21 (22.8\%) patients in the
ERAS group reported slight and moderate pain, respectively, and $7(7.6 \%)$ and 1 (1.1\%) patients experienced "a lot" and "enormous" pain, respectively. Lee et al. ${ }^{(22)}$ reported that patients in the laparoscopic group reported better pain control $(p<0.0001)$ and nausea control $(p=0.003)$ during recovery. This included increased ability to put on their clothes $(p=0.001)$ and confidence in mobility $(\mathrm{p}<0.0001)$ and in going home 
$(\mathrm{p}<0.0001)$. Weston et al. ${ }^{(32)}$ reported that the pain scores in the ERAS group were lower than those in other patient groups when controlling for oral morphine equivalency (mean 3.6 vs 4.1, $\mathrm{p}=0.03)$. Wodlin et al. ${ }^{(30)}$ reported that the most common postoperative symptoms were pain, nausea, vomiting, itching, drowsiness, and fatigue. Abdominal pain, drowsiness, and fatigue occurred significantly less often and with lower intensity in the spinal anesthesia group. Spinal anesthesia was associated with a higher prevalence of postoperative itching ${ }^{(30)}$. As regards the ERAS in gynecologic surgery and return to bowel function, Xiromeritis et al. ${ }^{(31)}$ reported significantly low visual analog scale scores for postoperative pain, earlier return of bowel peristalsis, and fewer hospitalization hours in the group who received multimodal analgesia.

\section{Readmission Rate}

Ferraioli et al. ${ }^{(34)}$ reported that 12 patients required additional postoperative care. This included four patients who were readmitted to the hospital, five were managed on an outpatient basis, and three had a prolonged LOS because of early postoperative complications. de Lapasse et al. ${ }^{(38)}$ reported that $2(6.7 \%)$ patients required admission because of complications. The first patient required hospitalization for a vesicovaginal fistula on day 10 and had to undergo laparoscopic treatment of the fistula. The other patient consulted for hyperthermia on day 4 with a suggestion of cuff cellulitis and was discharged after 2 days of antibiotic treatment. Ottesen et al. ${ }^{(37)}$ reported no readmissions in patients who underwent surgery under ERAS protocol. Peters et al. ${ }^{(36)}$ found that hospital readmission rates (CPC: $2.3 \%$ vs ERAS: $3.1 \%$; p<0.584) were comparable.

\section{Discussion}

This review revealed and highlighted the importance of ERAS implementations perioperatively in gynecologic surgery. In this study, commonly measured attributes of surgical recovery were reviewed and analyzed using the ERAS protocol from a gynecologic perspective. With regard to the reported outcomes, the ERAS protocol appears to have positive effects on patients both clinically and psychologically. In addition to being the most recent, our review is more comprehensive than previous endeavors and includes cohort and retrospective analysis not covered in previous reviews. The systematic review by Kalogera et al. ${ }^{(21)}$ in 2019 concluded that ERAS implementation in gynecologic surgery represents the best clinical practice and should be adopted across gynecological surgical procedures. Despite the lack of conflict between the results of our review and those of their review, we would not be in favor of such a strong recommendation, which we believe should be reserved for the day when more diverse and high-quality data allow a full meta-analysis of this critical topic. However, we concur that ERAS protocols in gynecologic surgery appear to improve postoperative pain, satisfaction, and decrease LOS in appropriate patients. ERAS protocols have the potential for universal adoption across gynecologic surgeries if further RCTs and high-quality studies continue to report similar results.

As regards opioid use, Weston et al. ${ }^{(32)}$ concluded that the implementation of the ERAS protocol after MIS is an effective method to reduce opioid use. In addition, Wodlin et al. ${ }^{(31)}$ reported that spinal anesthesia appears to reduce the need for opioids postoperatively. They also reported that spinal anesthesia with intrathecal morphine demonstrated favorable effects on postoperative symptoms and recovery following fasttrack abdominal hysterectomy ${ }^{(30)}$. In the setting of minimally invasive myomectomy, Xiromeritis et al. ${ }^{(31)}$ reported that the implementation of a multimodal analgesic protocol improved postoperative recovery, resulting in earlier hospital discharge. Ljungqvist et al. ${ }^{(40)}$ and Helou et al. ${ }^{(41)}$ concluded that ERAS could enhance postoperative outcomes, satisfaction, and care costs for most patients undergoing gynecologic surgery. However, Helou et al. ${ }^{(41)}$ also stated that some modifications to the current ERAS protocols may benefit specific subgroups of patients, including patients with chronic pelvic pain, opiate dependence, or psychiatric disorders. Wong et al. ${ }^{(42)}$ concluded that with ERAS, minimally invasive gynecologic surgeons could help minimize and manage postoperative pain with less dependence on opioid medications. In his review, Bajsová concluded $^{(43)}$ that the implementation of an ERAS protocol could lead to a reduction in complications of up to $40 \%$ and a reduction in hospitalizations of up to 30\% and thus reducing the overall costs without increasing the rehospitalization rate.

As regards the audit of surgical practice, Wijk et al. ${ }^{(44)}$ concluded that with ERAS guidelines, surgical practice demonstrates improvements in compliance and clinical outcomes, including LOS.

The strength of this study lies in our comprehensive search of the current literature to obtain the highest and most dependable level of evidence regarding perioperative implementation of the ERAS protocol in gynecologic surgery up to this point. This review included most study designs to ensure a large sample size. However, weaknesses include the moderate overall quality of the included studies and insufficient data for meta-analysis. Further studies with larger sample sizes and longer follow-up are essential to involve more ERAS outcomes.

\section{Conclusion}

In conclusion, ERAS implementation showed a clinically significant improvement in patient recovery postoperatively, including postoperative pain, readmission rates, and satisfaction. Further studies are necessary to formulate stronger, broader recommendations regarding the adoption of ERAS protocols across gynecologic surgeries.

\section{Ethics}

Peer-review: Internally peer-reviewed.

\section{Authorship Contributions}

Concept: J.P., Design: A.A., Data Collection or Processing: C.C., S.R., Analysis or Interpretation: G.B., K.C., Literature 
Search: G.J.M., C.C., A.T., A.K., S.R., G.B., K.C., N.C., H.U., J.P., A.A., K.S., Writing: G.J.M.

Conflict of Interest: The authors report no conflict of interest. Financial Disclosure: Authors have no financial interests about the research.

\section{References}

1. Kehlet H, Wilmore DW. Evidence-based surgical care and the evolution of fast-track surgery. Ann Surg 2008;248:189-98.

2. Kehlet H, Wilmore DW. Multimodal strategies to improve surgical outcome. Am J Surg 2002;183:630-41.

3. Varadhan KK, Neal KR, Dejong CH, Fearon KC, Ljungqvist O, Lobo DN. The enhanced recovery after surgery (ERAS) pathway for patients undergoing major elective open colorectal surgery: a metaanalysis of randomized controlled trials. Clin Nutr 2010;29:434-40.

4. Ljungqvist O. Jonathan E. Rhoads lecture 2011: insulin resistance and enhanced recovery after surgery. JPEN J Parenter Enteral Nutr 2012;36:389-98

5. Greco M, Capretti G, Beretta L, Gemma M, Pecorelli N, Braga M. Enhanced recovery program in colorectal surgery: a meta-analysis of randomized controlled trials. World J Surg 2014;38:1531-41.

6. Geltzeiler CB, Rotramel A, Wilson C, Deng L, Whiteford MH, Frankhouse J. Prospective study of colorectal enhanced recovery after surgery in a community hospital. JAMA Surg 2014;149:95561.

7. Auyong DB, Allen CJ, Pahang JA, Clabeaux JJ, MacDonald KM, Hanson NA. Reduced length of hospitalization in primary total knee arthroplasty patients using an updated enhanced recovery after orthopedic surgery (ERAS) pathway. J Arthroplasty 2015;30:17059.

8. Trowbridge ER, Dreisbach CN, Sarosiek BM, Dunbar CP, Evans SL, Hahn LA, et al. Review of enhanced recovery programs in benign gynecologic surgery. Int Urogynecol J 2018;29:3-11.

9. de Groot JJ, Ament SM, Maessen JM, Dejong CH, Kleijnen JM, Slangen BF. Enhanced recovery pathways in abdominal gynecologic surgery: a systematic review and meta-analysis. Acta Obstet Gynecol Scand 2016;95:382-95.

10. Nelson G, Kalogera E, Dowdy SC. Enhanced recovery pathways in gynecologic oncology. Gynecol Oncol 2014;135:586-94.

11. Nelson G, Altman AD, Nick A, Meyer LA, Ramirez PT, Achtari C, et al. Guidelines for pre- and intra-operative care in gynecologic/ oncology surgery: enhanced Recovery After Surgery (ERAS®) Society recommendations--Part I. Gynecol Oncol 2016;140:31322.

12. Nelson G, Altman AD, Nick A, Meyer LA, Ramirez PT, Achtari C, et al. Guidelines for postoperative care in gynecologic/oncology surgery: Enhanced Recovery After Surgery (ERAS®) Society recommendations--Part II. Gynecol Oncol 2016;140:323-32.

13. Waller A, Forshaw K, Bryant J, Carey M, Boyes A, Sanson-Fisher R. Preparatory education for cancer patients undergoing surgery: a systematic review of volume and quality of research output over time. Patient Educ Couns 2015:S0738-3991(15)00229-3. doi: 10.1016/j.pec.2015.05.008. Epub ahead of print.

14. Egbert LD, Battit GE, Welch CE, Bartlett MK. Reduction of postoperative pain by encouragement and instruction of patients: a study of doctor-patient rapport. N Eng J Med 1964;270:825-7.

15. Kalogera E, Dowdy SC. Enhanced recovery pathway in gynecologic surgery: improving outcomes through evidence-based medicine. Obstet Gynecol Clin North Am 2016;43:551-73.
16. Ajori L, Nazari L, Mazloomfard MM, Amiri Z. Effects of gabapentin on postoperative pain, nausea and vomiting after abdominal hysterectomy: a double blind randomized clinical trial. Arch Gynecol Obstet 2012;285:677-82.

17. Maund E, McDaid C, Rice S, Wright K, Jenkins B, Woolacott N. Paracetamol and selective and non-selective non-steroidal antiinflammatory drugs for the reduction in morphine-related sideeffects after major surgery: a systematic review. Br J Anaesth 2011;106:292-7.

18. Wick EC, Grant MC, Wu CL. Postoperative multimodal analgesia pain management with nonopioid analgesics and techniques: a review. JAMA Surg 2017;152:691-7.

19. Lambaudie E, de Nonneville A, Brun C, Laplane C, N'Guyen Duong L, Boher JM, et al. Enhanced recovery after surgery program in gynaecologic oncological surgery in a minimally invasive techniques expert center. BMC Surg 2017;17:136.

20. Modesitt SC, Sarosiek BM, Trowbridge ER, Redick DL, Shah PM, Thiele RH, et al. Enhanced Recovery Implementation in Major Gynecologic Surgeries: Effect of Care Standardization. Obstet Gynecol 2016;128:457-66.

21. Kalogera E, Glaser GE, Kumar A, Dowdy SC, Langstraat CL. Enhanced recovery after minimally invasive gynecologic procedures with bowel surgery: a systematic review. J Minim Invasive Gynecol 2019;26:288-98.

22. Lee J, Asher V, Nair A, White V, Brocklehurst C, Traves M, et al. Comparing the experience of enhanced recovery programme for gynaecological patients undergoing laparoscopic versus open gynaecological surgery: a prospective study. Perioper Med (Lond) 2018;7:15.

23. Michener CM, Lampert E, Yao M, Harnegie MP, Chalif J, Chambers LM. Meta-analysis of laparoendoscopic single-site and vaginal natural orifice transluminal endoscopic hysterectomy compared with multiport hysterectomy: real benefits or diminishing returns? J Minim Invasive Gynecol 2021;28:698-709.

24. National Heart, Lung, and Blood Institute. Study Quality Assessment Tools Available from: https://www. nhlbi. nih. gov/health-topics/ study-quality-assessment-tools.

25. Chapman JS, Roddy E, Ueda S, Brooks R, Chen LL, Chen LM. Enhanced recovery pathways for improving outcomes after minimally invasive gynecologic oncology surgery. Obstet Gynecol 2016;128:138-44.

26. Frumovitz M, Obermair A, Coleman RL, Pareja R, Lopez A, Ribero $\mathrm{R}$, et al. Quality of life in patients with cervical cancer after open versus minimally invasive radical hysterectomy (LACC): a secondary outcome of a multicentre, randomised, open-label, phase 3, noninferiority trial. Lancet Oncol 2020;21:e341doi: 10.1016/S14702045(20)30081-4.

27. Kroon UB, Rådström M, Hjelthe C, Dahlin C, Kroon L. Fast-track hysterectomy: a randomised, controlled study. Eur J Obstet Gynecol Reprod Biol 2010;151:203-7.

28. Pauls RN, Crisp CC, Oakley SH, Westermann LB, Mazloomdoost D, Kleeman SD, et al. Effects of dexamethasone on quality of recovery following vaginal surgery: a randomized trial. Am J Obstet Gynecol 2015;213:718.e1-7. doi: 10.1016/j.ajog.2015.05.061

29. Ravndal C, Vandrevala T. Preemptive local anesthetic in gynecologic laparoscopy and postoperative movement-evoked pain: a randomized trial. J Minim Invasive Gynecol 2016;23:775-80.

30. Wodlin NB, Nilsson L, Arestedt K, Kjølhede P; 'GASPI' Study Group. Mode of anesthesia and postoperative symptoms following 
abdominal hysterectomy in a fast-track setting. Acta Obstet Gynecol Scand 2011;90:369-79.

31. Xiromeritis P, Kalogiannidis I, Papadopoulos E, Prapas N, Prapas $\mathrm{Y}$. Improved recovery using multimodal perioperative analgesia in minimally invasive myomectomy: a randomised study. Aust N Z J Obstet Gynaecol 2011;51:301-6.

32. Weston E, Noel M, Douglas K, Terrones K, Grumbine F, Stone R, et al. The impact of an enhanced recovery after minimally invasive surgery program on opioid use in gynecologic oncology patients undergoing hysterectomy. Gynecol Oncol 2020;157:469-75.

33. Dickson E, Argenta PA, Reichert JA. Results of introducing a rapid recovery program for total abdominal hysterectomy. Gynecol Obstet Invest 2012;73:21-5.

34. Ferraioli D, Pouliquen C, Jauffret C, Charavil A, Blache G, Faucher $\mathrm{M}$, et al. EVAN-G score in patients undergoing minimally invasive gynecology oncologic surgery in an Enhanced Recovery After Surgery (ERAS) program. Int J Gynecol Cancer 2020;30:1966-74.

35. Kanno K, Andou M, Yanai S, Toeda M, Nimura R, Ichikawa F, et al. Y. Long-term oncological outcomes of minimally invasive radical hysterectomy for early-stage cervical cancer: A retrospective, singleinstitutional study in the wake of the LACC trial. J Obstet Gynaecol Res 2019;45:2425-34.

36. Peters A, Siripong N, Wang L, Donnellan NM. Enhanced recovery after surgery outcomes in minimally invasive nonhysterectomy gynecologic procedures. Am J Obstet Gynecol 2020;223:234.el-e8.

37. Ottesen M, Sørensen M, Rasmussen Y, Smidt-Jensen S, Kehlet H, Ottesen B. Fast track vaginal surgery. Acta Obstet Gynecol Scand 2002;81:138-46.
38. de Lapasse C, Rabischong B, Bolandard F, Canis M, Botchorischvili $\mathrm{R}$, Jardon $\mathrm{K}$, et al. Total laparoscopic hysterectomy and early discharge: satisfaction and feasibility study. J Minim Invasive Gynecol 2008;1:20-5.

39. Yoong W, Sivashanmugarajan V, Relph S, Bell A, Fajemirokun E, Davies T, et al. Enhanced Recovery After Surgery (ERAS) Team for Gynaecology and Anaesthesia. Can enhanced recovery pathways improve outcomes of vaginal hysterectomy? Cohort control study. J Minim Invasive Gynecol 2014;21:83-9.

40. Ljungqvist $\mathrm{O}$, Scott M, Fearon KC. Enhanced recovery after surgery: a review. JAMA Surg 2017;152:292-8.

41. Helou CM, Chaves KF, Limperg TB, Anderson TL. Enhanced recovery after surgery in minimally invasive gynecologic surgery surgical patients: one size fits all? Curr Opin Obstet Gynecol 2020;32:248-54.

42. Wong M, Morris S, Wang K, Simpson K. Managing postoperative pain after minimally invasive gynecologic surgery in the era of the opioid epidemic. J Minim Invasive Gynecol 2018;25:1165-78.

43. Bajsová S, Klát J. ERAS protocol in gynecologic oncology. Ceska Gynekol 2019;84:376-85. (English)

44. Wijk L, Udumyan R, Pache B, Altman AD, Williams LL, Elias KM, et al. International validation of Enhanced Recovery After Surgery Society guidelines on enhanced recovery for gynecologic surgery. Am J Obstet Gynecol 2019;221:237.e-1e11. doi: 10.1016/j. ajog.2019.04.028. 